Dossiê: Narrativas

\title{
A vingança do curso de ação contra a ilusão cientificista
}

\section{Courses of action's revenge against the scientistic illusion}

Daniel Bertaux*

Resumo: O nascimento e desenvolvimento da sociologia acadêmica foi facilitada enormemente pela crença "cientificista" -compartilhada pela maioria dos seus fundadores, especialmente Comte e Durkheim e revitalizada pelo estruturalismo de Bourdieu-, da possibilidade das ciências da sociedade não serem substancialmente diferentes das "outras ciências", ou seja, das ciências naturais. Contudo, não há nenhuma ação auto-determinada a ser encontrada na natureza, nenhum curso de ação direcionado para algum objetivo ou para conviç̧ões fortes ("valores"); não há nenhum sujeito de ação no mundo da física. Entretanto, a fim de defender uma crença que -embora falsa- fez tanto e ainda faz muito para consolidar o status científico da sociologia, seus principais autores foram e permaneceram relutantes em considerar -como fez Weberque os cursos de ação individuais ao longo do tempo constituem o elemento central na produção e mudança de sociedades modernas. E cinquenta anos após o nascimento do construtivismo, estes autores ainda encaram com grande suspeita o único método empírico que permite reconstruir cursos individuais de ação (situada), a entrevista narrativa ou "história de vida". Não que este método faça milagres; mas se tomado seriamente, pode mudar a maneira como sociólogos olham para as sociedades: não como "sistemas" estáticos, mas como conjuntos dinâmicos e sempre em transformação.

Palavras-chave: Cientificismo. Estruturalismo. Curso de ação. Trabalho autônomo. História de vida.

\begin{abstract}
The birth and development of academic sociology has been greatly facilitated by the 'scientistic' belief, shared by most of its founding fathers and especially Comte and Durkheim and revitalized by Bourdieu's structuralism, in the possibility of a science of society that would not be fundamentally different from 'the other sciences'; i. e. the natural sciences. There is not however in nature any self-determined action to be found, no courses of action focused on some goal or on some hard conviction ('value'); there is no subject of action in the world of physics. Nevertheless, in order

* Diretor de pesquisa (emérito) do Centro Nacional Francês de Pesquisa Científica na Universidade de Estrasburgo, França (Laboratório de Dinâmicas Europeias) < daniel.bertaux@, misha.fr>. Tradução do francês de Hermílio Santos.
\end{abstract}

\begin{tabular}{|c|c|c|c|c|c|}
\hline Civitas & Porto Alegre & v. 14 & n. 2 & p. $250-271$ & maio-ago. 2014 \\
\hline
\end{tabular}


to defend a belief that -however false- had done and is doing so much to consolidate the scientific status of sociology, its establishment was and has remained consistently reluctant to consider - as Weber had done- that individual courses of action through time constitute the core element in producing and changing modern societies. And fifty years after the birth of constructivism, this establishment still looks with great suspicion at the only empirical method that allows reconstructing individual courses of (situated) action, the narrative interview or 'life story'. Not that this method makes miracles; but if taken seriously, it might change the way sociologists look at societies: not as static 'systems' but as dynamic and ever-changing ensembles.

Keywords: Scientism. Structuralism. Course of action. Self-employment. Life story.

\section{Introdução}

Há quarenta anos, sobretudo a partir do surgimento da obra revolucionária de Peter Berger e Thomas Luckmann A construção social da realidade (1966), os sociólogos começaram a compreender que o que fazem os membros de uma sociedade, não apenas coletivamente, mas individualmente, sua ação, não somente instantânea (seu comportamento), mas na durée, contribui fortemente para orientar o destino desta sociedade, para construir seu devenir histórico.

Mas se a concepção construtivista continua a se difundir na sociologia, ela encontra uma forte resistência da parte do cientificismo $^{1}$ que reina desde o início da nossa disciplina, notadamente na França e no mundo anglosaxão; e assim a hegemonia persiste -notadamente em razão de interesses corporativistas- a despeito de críticas recorrentes. Aqui quero acentuar uma de suas consequências nefastas: a total ausência de interesse da sociologia dominante pelos cursos de ação (individual) na durée, que permanece no âmbito do impensável e sobretudo, do não-observado; ou mesmo do nãoobservável. De fato, esta sociologia não somente nunca desenvolveu uma técnica de observação empírica para observá-los; mas mais que isso, quando uma técnica foi proposta-sob a forma de entrevista narrativa, que compreende a narrativa biográfica- ela a rejeitou como ilegítima com o maior vigor, como se os cientistas quisessem negar sua própria existência, pois o reconhecimento viria a fragilizar consideravelmente a influência da ilusão cientificista.

\footnotetext{
1 Por cientificismo designarei aqui a ideia, a crença, o discurso segundo o qual a sociologia (e as outras ciências sociais), para desenvolver conhecimentos verdadeiramente científicos, deve seguir rigorosamente o exemplo das ciências naturais. Ao longo da minha juventude de estudante recebi uma formação científica avançada; e trabalhei como engenheiro-pesquisador antes de bifurcar para a pesquisa sociológica. Conhecendo os dois universos, tenho a convicção que a crença cientificista é profundamente equivocada.
} 


\section{A ilusão cientificista}

Segundo Wolf Lepenies (1996), que detalhou a emergência da sociologia como uma nova disciplina na França, na Alemanha e na Grã-Bretanha, tratase de três aventuras bastante diferentes. Em torno do fim de um século 19, dominado pelo progresso espetacular das ciências da natureza e suas inúmeras aplicações técnicas, a ideia mesma de conhecimento não poderia deixar de ser profundamente influenciada por seu sucesso retumbante e o progresso que ela prometia. Para que a sociologia se tornasse científica parecia evidente que ela deveria se desvincular da filosofia, e sobretudo da literatura e das artes, e fingir esquecer que o mundo natural estudado pela ciência consiste de "coisas" inanimadas impulsionadas por forças eternas e onipresentes, enquanto o mundo humano é composto principalmente de seres vivos ativos, reflexivos e singulares, que por suas ações se tornam o que ele é e o que se tornará...

$\mathrm{Na}$ França, a afirmação -tipicamente cientificista- de que a sociologia se construiu sobre o modelo das ciências da natureza ajudou consideravelmente os fundadores da sociologia, notadamente Auguste Comte e Emile Durkheim, a consolidar seu estatuto "científico" (e dos fundadores na mesma ocasião). E é este estatuto, conquistado ao preço de um trabalho intenso e de lutas amargas, que os sucessores de Durkheim -notadamente Bourdieu $\sim^{2}$ defenderam com vigor.

Certamente que o pensamento de Bourdieu ainda não conseguiu, apesar de seus esforços e dos inúmeros sociólogos que ele formou, conquistar a hegemonia absoluta na sociologia francesa. Contudo, é fraca a influência de

2 Bourdieu é um dos que, no mundo inteiro, mais claramente afirmou e reafirmou a ideia cientificista. Assim: "A sociologia é uma ciência como as outras ciências", em Questions de sociologie (Bourdieu, 1980); pela expressão "as outras ciências" Bourdieu designa as ciências da natureza, em primeiro lugar a física. O texto de referência é aqui o longo artigo de Pierre Bourdieu e Jean-Claude Passeron (1967) Sociology and philosophy in France since 1945: death and resurrection of a philosophy without subject. Seu título indica de maneira explícita que a sociologia não pode se desenvolver no âmbito de uma "filosofia do sujeito", como faz Sartre, que acentua a liberdade de cada um. Toda a obra ulterior de Bourdieu confirma que para ele Durkheim -e não Marx ou Max Weber- que é o verdadeiro fundador da sociologia enquanto ciência (ele insiste nesse termo) dos fenômenos sociais propriamente coletivos. A revolução estruturalista do início dos anos 1960 em Paris (Levi-Strauss, Althusser, Lacan...), da qual Bourdieu e Passeron participaram com entusiasmo, significou -contra Sartre- o retorno com vigor de uma "filosofia sem sujeito". Ver também como outro exemplo de construção sofisticada de ilusão cientificista, Le métier de sociologue, de Bourdieu, Passeron e Chamboredon (1968), uma obra que influenciou profundamente duas ou três gerações de sociólogos na França, até os dias de hoje inclusive. Depois de Durkheim, o autor citado com mais frequência nesse texto é Gaston Bachelard, um filósofo que conhecia muito bem a história das ciência naturais. Passeron em seguida se deu conta das contradições internas da ilusão cientificista, e rompeu com ela (e com Bourdieu) em sua obra Le raisonnement sociologique (1991). 
outros espíritos criativos tais como Edgar Morin ou Cornelius Castoriadis. Do ponto de vista que nos interessa aqui, aquele das concepções sociológicas da ação individual, é Raymond Boudon quem, a partir dos anos 1970, virando as costas deliberadamente para toda a tradição sociológica de focalização no poder do coletivo, procurou reconstruir toda a sociologia a partir da ação individual e "das boas razões" - que ele não reduz ao interesse individual-que os indivíduos agem de tal ou tal maneira. Sua forma de pensar é relativamente bem estabelecida, mas claramente minoritária.

Na Grã-Bretanha, emergindo diante das "duas culturas" (C. P. Snow) do humanismo e das ciências, culturas já fortemente consolidadas mas mutualmente hostis, a sociologia escolheu o lado das ciências.

Nos Estados Unidos, pátria do pragmatismo, foi de outra maneira. E efetivamente, o caminho em direção ao cientificismo foi bastante diferente. Penso que ele passou pela etapa bastante marcante da invenção do survey research, imediatamente seguida por sua difusão relâmpago a partir dos anos 1940. A utilidade prática do survey, sua utilização intensa para objetivos não apenas sociográficos, mas também eleitorais ou comerciais foi acompanhada de um discurso apresentando-o como $o$ método científico, que transformou a sociologia em uma verdadeira ciência. Ora, se o survey, método extensivo, constitui uma técnica excepcionalmente rentável para descrever a distribuição estatística de algumas "variáveis" individuais em uma população muito numerosa, vincular as associações estatísticas entre variáveis a "relações causais" é um exercício delicado. E afirmar que essas relações causais são o equivalente, para a sociedade, às leis físicas para o mundo inanimado é uma fraude. Mas que foi repetida tão frequentemente e ensinada nas universidades, e tão bem empacotada, encoberta e mascarada por roupagens matemáticas enganosas, que quase todos acreditaram... Ora, esta crença serviu a todo mundo (salvo àqueles que procuravam verdadeiramente compreender as lógicas encobertas da vida social); de fato, não apenas os sociólogos, mas os meios de comunicação, as instituições financeiras e os partidos políticos encontraram seus interesses. Então a crença inchou, inchou, inchou...ao ponto de se tornar too big to fail. O estatuto (usurpado) de "ciência como as outras" é nosso patrimônio comum: e compreendemos as imensas reticências a tocá-la... ${ }^{3}$

\footnotetext{
3 Não conheço muito a sociologia alemã contemporânea para falar aqui. Mas é claro que Dilthey, depois Weber e Simmel desenvolveram uma visão diferente da vocação da sociedade, bastante menos cientificista, bastante mais coerente com sua verdadeira vocação. Dilthey foi o primeiro a conseguir abrir, entre o espaço da literatura (e da poesia, ver Lepenies, 1996) e o espaço das ciências, um terceiro espaço: um espaço especifico para as Geisteswissenschaften -as ciências do espírito- que seus sucessores preferiram designar pela expressão mais precisa de
} 


\section{A ação individual na durée: os cursos de ação localizada}

Há muito tempo que os historiadores -alguns dos quais são melhores conhecedores da sociedade que eles estudam que muitos sociólogosabandonaram a ideia de destino histórico predeteminado (pela geografia, pelo modelo cultural, pelo progresso tecnológico...). Eles estão conscientes do lugar que ocupam, na orientação do curso histórico de um estado-nação, as ações de uma variedade de atores individuais cuja eficácia é multiplicada pelos recursos de poder que dispõe cada um deles em função de sua posição nas instituições e/ou nas redes de interconhecimento e de convivência.

Mas muitos sociólogos -e a maioria dos economistas- ainda se apegam à ilusão cientificista. Para que esta ilusão seja plausível é preciso antes retirar a ideia que no interior da sociedade há quantidades importantes de ação individual não-predeterminada, de ação livre, autodeterminada ou pelo menos relativamente autônoma. É com este alvo que se construiu a figura, o tipo ideal do homo economicus movido exclusivamente por seu interesse de curto prazo: pode-se assim deduzir todas suas ações dos seus interesses e reduzi-los assim ao predeterminado.

Na sociologia temos a escolha entre vários tipos de redução. A ação individual pode ser ditada pela conformidade às normas (Durkheim); pela busca do interesse individual (rational choice, "boas razões" de Boudon); ou surgidas mecanicamente do habitus, estrutura estruturada pelas experiências da infância que funciona depois como estrutura estruturante da conduta na idade adulta (Bourdieu). Evidente que a negação da autonomia relativa da ação seria mais eficaz se todos os sociólogos concordassem com a mesma redução... mas o importante não é finalmente se livrar desta autonomia que torna a ação imprevisível, que torna a realidade sócio-histórica não predeterminada e que ameaça a cientificidade da sociologia e da economia política.

Além disso, todas as formas de ação não ameaçam a ilusão cientificista: a ação constrangida, a ação comandada a partir do exterior em função de relações hierárquicas -o trabalho de um operário semi-qualificado, por exemplo- não a coloca em questão. Ela se faz porque o indivíduo-agente é constrangido por

\footnotetext{
Kulturwissenschaften (ciências da cultura). Este espaço parece-me ser efetivamente o espaço onde pode florescer não apenas a sociologia, mas também as outras ciências sociais, incluindo -apesar de sua aparência de cientificidade- as "ciências econômicas", cujo objeto é bastante mais intimamente conectado à política que seu discurso admite; e evidentemente as ciências humanas, a história, a filosofia... Este espaço possui seu próprio regime de verdade, que por não poder colocar em prática o método experimental- é diferente do regime (hipotéticodedutivo) das ciências da natureza.
} 
sua posição inferior em um sistema de relações de poder (incluindo as relações de propriedade); ela é, portanto, previsível.

É a ação livre, aquela que compõe a iniciativa do ator, que é problemática: quando este operário da fábrica passa seus fins-de-semana construindo sua própria casa, ele não trabalha mais para um outro; ele realiza seu próprio projeto. ${ }^{4}$ Não se trata de uma simples conduta, menos ainda de um comportamento instantâneo; trata-se, ao contrário, de um curso de ação (relativamente autônomo) se inscrevendo na durée.

\section{O que se entende por "curso de ação"?}

Os textos dos pais fundadores da sociologia tratam com muito mais frequência de "estruturas" e de constrangimentos que de ação; e quando falam de ação é frequentemente em termos de ação coletiva. Eles parecem considerar que, do ponto de vista da sociologia, a ação individual não é importante. Max Weber foi o único a considerar seriamente a ação individual "livre", ou pelo menos relativamente autônoma. Ele nos legou -tardiamente- uma tipologia notavelmente precisa de lógicas de ação. Mas ele deixou aos nossos cuidados desenvolvê-la.

O que importa aqui é antes de tudo livrar a ação da prisão behaviorista onde a survey research a aprisionou durante muito tempo. Pois a ação humana não se reduz, longe disso, a comportamentos instantâneos, sem densidade temporal, sem durée, tal como comportamentos eleitorais (votos) ou comportamentos econômicos (compras)... Ela se desenrola na durée, talvez ao longo de anos; antes mesmo de se traduzir em atos, ela nasce de um projeto, projeção em direção ao futuro; ela foi pensada, refletida, antecipada, traduzida em estratégia(s). Enquanto ela se desenvolve ela encontra obstáculos imprevistos que modificam seu curso; ela é sempre uma aventura de alguma maneira. E quando termina ela continua a viver de suas consequências: nossos atos marcantes nos seguem até a nossa morte.

O conceito que melhor traduz essas propriedades da ação na durée é o conceito de curso de ação. É o momento de introduzi-lo na sociologia. Ele se refere à sequência ordenada de ações que uma mesma pessoa executa na durée para, por exemplo, tentar realizar um de seus projetos (ação racional orientada a fins, zweckrationale Handlung, segundo Weber); ou para defender energicamente uma convicção profunda (wertrationale Handlung).

4 De um ponto de vista moral apenas podemos nos alegrar: este homem utiliza sua liberdade. "O homem se define por seu projeto", afirmou Sartre. Mas do ponto de vista do projeto cientificista, o fato de que ele utiliza sua liberdade para tomar a iniciativa de se engajar em um curso de ação de longo prazo, sem estar constrangido, é catastrófico. 
A ação é sempre ação localizada: pois o ator individual não age no vazio, mas ao contrário, no desenrolar de uma sociedade já constituída e habitada por diversos outros atores, distintamente providos de recursos e que podem estar organizados em instituições, em redes...5

Esses cursos de ação na durée são o que fazem, por elas e pelo que trazem, o sentido de sua vida como vida ativa. Mas num nível mais macro, ou mais "agregado" (Boudon), eles participam também na construção incessante do devenir sócio-histórico.

Para alimentar o conceito de cursos de ação com exemplos, consideremos primeiro aqueles que estão orientados à realização de um projeto preciso. Esse projeto pode ser do tipo educativo (obter tal diploma, passar em tal ou tal exame ou concurso); do tipo entrar no mundo do trabalho (procurar um primeiro emprego; encontrar um emprego no qual se sente bem); do tipo profissional (obter uma promoção específica; se estabelecer por conta própria, criando uma empresa); do tipo residencial (passar da condição de inquilino àquela de proprietário de sua moradia; tomar a iniciativa de migrar, isto é, de mudar de cidade, de região, de pais...); do tipo interpessoal (se fazer amar por uma pessoa específica); do tipo gerador (colocar no mundo uma criança; educá-la ${ }^{6}$ ); de um tipo vinculado à saúde (curar-se de uma doença grave; livrar-se de um vício); do tipo transformação pessoal (treinamento físico, ou psíquico; nova aprendizagem na idade adulta); ou ainda de outros tipos.

Apesar de sua grande variedade, esses cursos de ação possuem alguns pontos em comum. Eles são conduzidos por indivíduos, que tomaram a iniciativa de colocá-las em prática. Eles se inscrevem na durée. Em vista de sua realização recursos são mobilizados: recursos pessoais, aqueles que Bourdieu chama de "capitais", mas também recursos subjetivos (Delcroix, 2004); e recursos de poder ou "de posição", pois vinculados à posição socioprofissional do ator. Seu sucesso não é garantido. Eles pressupõem um grau importante de planejamento e de antecipação, mas encontram obstáculos imprevistos, ou oposições inicialmente subestimadas. Eles podem ser abandonados no percurso porque muito custosos, muito difíceis, ou perderam seu sentido inicial. Enfim, a questão do "sentido visado" pelo autor do curso de ação aqui é primordial, como Weber já havia assinalado com razão.

A título de hipótese eu acrescentaria um último ponto comum que, de maneira inesperada, parece emergir dessa lista de exemplos: todos esses

5 Parece que a filósofa e antropóloga Lucy Suchman (1987) foi a primeira a centrar sua atenção sobre a ideia de curso de ação situada.

6 Para qualificar a relação (positiva) dos adultos com crianças, o psicólogo Erik Erikson (1950) emprega o termo generatividade. 
cursos de ação têm por objetivo último uma mudança de condição (social) de seu autor. Por exemplo, de fazer passar da condição de estudante à de graduado. Da condição de jovem sem emprego, ou de desempregado, àquela de assalariado(a). Da condição de solteiro àquela de esposo ou esposa, e/ ou à condição de mãe e pai. Da condição de empregado àquela de dirigente. Da condição de inquilino à de proprietário. Da condição de assalariado à de empresário. Da condição de simples militante de um partido político àquela de candidato às eleições locais; e da condição de candidato àquela de eleito(a)... É compreensível portanto que esses cursos de ação mobilizem quantidades consideráveis de vontade, de inteligência e de energias individuais de ordem mental, física e moral (daí também a importância do suporte moral - dado pelos próximos).

Como não reconhecer que as quantidades consideráveis de energias individuais investidas, multiplicadas pelo número de pessoas que tomam a iniciativa de se engajar em tal ou tal curso de ação, possuem de fato poder sobre o futuro das sociedades $?^{7}$ A soma acumulada de cursos de ação individuais só pode contribuir na mudança social "a partir de baixo".

É o exemplo de migrações do campo para a cidade: as ciências sociais estão habituadas, pelo cientificismo, a ver nisso fluxos coletivos, mas esses fluxos são distintos de agregação acumulada de centenas de milhares de aventuras individuais (certamente influenciadas umas pelas outras)? Da mesma forma, o aumento do nível de educação, especialmente de mulheres jovens, não resulta de uma decisão central e é apenas parcialmente previsível; no entanto, suas consequências sobre a demografia, o desenvolvimento econômico, o desenvolvimento "antropônico", 8 a participação das mulheres nas atividades políticas, enfim, na mudança da sociedade, são consideráveis.

Considere agora os cursos de ação orientadas a valores, por convicções profundas: políticas, religiosas, morais, humanitárias... Eles certamente estão presentes nas sociedades mais desenvolvidas (e onde predomina o individualismo sob diferentes formas - ver Bellah et al., 1985), bem menos numerosos que aqueles que estão orientados a objetivos individuas; contudo, contrariamente ao que faz acreditar a teoria da rational choice, eles são todas também racionais. Mas trata-se de uma outra racionalidade, que não é

\footnotetext{
7 Por isso nos regimes ditatoriais, e mais ainda nos regimes "totalitários", toda iniciativa individual é suspeita. Ela será perseguida sob todas as formas, até mesmo as menores.

8 Um termo que prefiro àquele de "desenvolvimento humano". Propus o neologismo de "antroponomia" em Destins personnels et structure de classe (Bertaux, 1977). Ele designa "a produção das próprias pessoas" (Marx), de seus corpos pelo consumo, as curas médicas e o care propriamente dito, de seu espírito pelas instituições educativas e as atividades culturais.
} 
instrumental, mas por conviç̧ão (wertrationale Handlung); trata-se aqui de razões do coração, em vez de razões ditadas pelo interesse material. ${ }^{9}$ Esses cursos de ação também participam na construção do futuro coletivo; mas de uma maneira distinta, frequentemente inovadora, arriscada, anticonformista $\mathrm{e}$, às vezes, radical.

É surpreendente que a sociologia, apesar da abundância de suas especulações teóricas, mostrou tão pouco interesse em tentar pensar os cursos de ação. E que ela nunca procurou -com exceção de W. I. Thomas-imaginar como, através de qual método empírico, se poderia observá-los para melhor conhecê-los, analisá-los, compreendê-lo. ${ }^{10}$

9 Ver Bertaux (1990) e Fraser et al. (1968). O ponto de vista segundo o qual a única ação racional é a ação instrumental orientada aos interesses individuais conduz muito diretamente à conclusão que resistir a um poder forte, ditatorial, é uma ação irracional. De acordo com esse ponto de vista - estranho- franceses que se juntaram à Resistência contra o invasor nazista em 1940 e 1941 agiram "irracionalmente"; somente aqueles, bem numerosos, que nessa época ofereceram sua colaboração à potência invasora agiram racionalmente...

${ }^{10}$ Weber, que nos legou postumamente uma tipologia extremamente pertinente das lógicas de ação, não se deu ao trabalho de precisar como se poderia estudá-las empiricamente. Creio -mas isso é apenas minha opinião- que se alguém, sua esposa por exemplo, lhe tivesse perguntado, ele teria respondido mais ou menos assim: "Bom, mein Kind, para dizer a verdade eu ainda não pensei. Mas se poderia começar por estudar as autobiografias, como Dilthey recomendou. $\mathrm{Na}$ época, admito, preocupado com questões que me pareciam mais fundamentais, eu de fato não havia entendido por que ele se interessava tanto por isso. Mas, Marianne, isso não é suficiente, natürlich! Pois as pessoas que escrevem suas autobiografias são a exceção, não é? Deve-se encontrar outra coisa; uma maneira de ter acesso ao conhecimento empírico dos cursos de ação dos indivíduos em todos os ambientes sociais. É fundamental! A introspecção não é suficiente! Tentar imaginar como fazem as pessoas de outras posições de classe é um exercício perigoso: a maior parte do tempo "damos com os burros n'água", o nariz em seu etnocentrismo de classe! (risos) Deixemos esse ridiculo aos filósofos, que se tomam eles próprios como uma encarnação singular do Universo. E as mulheres, Marianne, e os cursos de ação das mulheres? Você conhece um único homem que poderia imaginar? É bastante sutil. Como elas fazem, mein Kind, você sabe disso mais que eu; a única certeza que tenho sobre a questão é que não sei nada... (risos). Não; somos burgueses, de um tipo particular sem dúvida, mais ou menos, espero; mas ainda assim burgueses. Não vamos acreditar que podemos nos colocar no lugar dos outros, daqueles que vivem toda sua vida em uma outra posição de classe, com seus próprios horizontes de significação que são muito diferentes dos nossos. Deve-se apenas saber que nós não sabemos grande coisa deles. Ser consciente que se deve descobrir pela pesquisa; e que quando nós descobrirmos ficaremos provavelmente primeiro chocados em nossos valores morais! Como eles próprios ficariam chocados de descobrir como nós vivemos (risos). Sim, deve-se perguntar a eles, simplesmente, como eles fazem para viver como eles vivem. E sem se revoltar quase nunca: isto é o mais incrivel, não é Marianne? Mas você sabe por quê? Sem dúvida é porque eles estão muito preocupados com suas chances de realizar seus projetos individuais; chances que eles não querem colocar em perigo se juntando a um projeto de ação coletiva, cujo resultado lhes parece bastante aleatório. Pelo menos quando eles perseguem um projeto orientado a um fim ao qual tem todo apreço, eles sentem que eles controlam o desenvolvimento. Mas... Ach!, olha eu caindo no erro que eu estou denunciando: eu me projeto sobre os outros... Não! Repito, deve-se perguntar a eles, simplesmente. Sim, é isso: pedir a eles para que contem o que eles fizeram, o que eles fazem, para onde eles querem ir. E anotar cuidadosamente tudo o que eles dizem". 


\section{Um exemplo de curso de ação na durée: a passagem de assalariado a autônomo}

Diversos processos sociais centrais precisaram, para serem pensados, do conceito de curso de ação. Por exemplo, a figura do self-made man nos Estados Unidos. No imaginário dos estadunidenses, sua sociedade é "the land of opportunity". Os exemplos de conquista social individual são celebrados por todos os meios de comunicação. Quando o presidente Lincoln dizia que ele queria uma sociedade estadunidense na qual qualquer um começaria sua vida como assalariado, depois se tornaria autônomo e finalmente se tornaria ele próprio empregador, ele fazia os estadunidenses sonhar.

Poder-se-ia esperar então que a sociologia norte-americana, com a força de seus 15.000 profissionais e seu interesse pela mobilidade social desde os anos 1950, teria multiplicado as pesquisas empíricas sobre os self-employed, sobre o self-employment; e sobretudo sobre a passagem sempre delicada do assalariado ao self-employment. No entanto, praticamente não se encontra, ainda hoje, pesquisa sociológica sobre esse fenômeno!

Como isso é possível? Para mim, esta é apenas uma das múltiplas consequências da recusa obstinada, pelo cientificismo hegemônico, de métodos de observação narrativa como o relato de vida.

Fiz parte, nos anos 1970, da rede internacional que estudou a mobilidade social por meio de grandes estudos estatísticos nacionais. Nós utilizamos instrumentos matemáticos sofisticados para analisar os dados quantitativos; e nós nos reuníamos regularmente, estadunidenses e europeus ocidentais, para comparar nossos resultados.

Mas nenhum de nós, nem mesmo os estadunidenses Robert Hauser e David Featherman, disse qualquer coisa precisa sobre as trajetórias da passagem do assalariado ao empreendedorismo através do self-employment em seu próprio país. Eu era o único que se interessava por essa questão; talvez porque eu era também o único marxista do grupo. Meus colegas estadunidenses me explicaram pacientemente que esse fenômeno dizia respeito somente a $10 \%$ da população: não faríamos portanto um survey nacional somente para esses $10 \% \ldots$

De fato, o único método empregado para estudar a mobilidade social, o survey, não convém de maneira alguma para observar esse fenômeno. Pois tornar-se autônomo é uma aventura de múltiplas facetas; e tentar em seguida desenvolver sua própria empresa é também uma aventura. É um curso de ação; e um curso de ação não se pode descrever com respostas a algumas questões pré-padronizadas. 


\section{Como descrever um curso de ação?}

Um curso de ação não se descreve: narra-se. Isso é o que Paul Ricoeur (2011) lembrou em sua obra fundamental, Tempo e narrativa. Desde que uma ação se inscreve na durée, deve-se necessariamente empregar a forma narrativa para descrevê-la (e se é o próprio ator que fala ou que escreve o que ele fez, ou, quando, como, com que meios, com que objetivo, com quem, contra quem etc. ele o fez, a história de vida -ou autobiografia-é a mais adequada).

Sim, eu o afirmo aqui: a lógica obriga a reconhecer o que o senso comum sempre soube, a saber, que para dizer o que foi um curso de ação, para descrever sua história e suas vicissitudes, tem-se que empregar a forma narrativa.

Para um espírito cientificista é uma conclusão profundamente chocante. De fato, nem os astrônomos, nem os físicos, nem os químicos, nem os geólogos jamais iriam pedir aos astros, às montanhas, aos oceanos ou às massas em movimento para lhes contar por que eles se movem como o fazem. Como eles sabem de antemão que eles não obteriam resposta, eles ficam satisfeitos em observar seus movimentos da maneira a mais precisa possível, inclusive -quando podem- fazendo variar de maneira experimental os parâmetros (Galileu). Para o sociólogo cientificista nós devíamos fazer o mesmo: observemos, meçamos com precisão, mas não esperemos nada dos "objetos humanos" que estudamos. Comportemo-nos como verdadeiros cientistas. ${ }^{11}$

Mas por que não? Observar a conduta dos indivíduos membros das sociedades humanas como fazem os especialistas em formigas, abelhas ou cupins levou e levará ainda a algumas descobertas. Este é, parece, o programa positivista no sentido não caricatural do termo. De uma certa forma, o programa do interacionismo simbólico, baseado na observação direta, se aproxima dele nesse ponto.

Mas isso levanta pelo menos dois problemas. Primeiro, em todo caso em que se pode observar diretamente as condutas, há a alternativa da abordagem weberiana: ela considera que os indivíduos sabem, ou ao menos pensam saber porque eles fazem o que fazem, e que sem dúvida seria bom de lhes perguntar; sem com isso aderir a todas as suas racionalizações que, de qualquer maneira, não estão elas próprias livres de interesses. Não é que em certos casos particulares, naqueles nos quais os indivíduos não podem comunicar o

${ }_{11}$ Não invento nada. Todos os sociólogos franceses conhecem a célebre frase retirada do Métier de sociologue (Bourdieu et al., 1968, p. 63): "A maldição das ciências humanas é talvez ter que lidar com objetos que falam". 
sentido de suas ações com o sociólogo, seja porque ele não fala sua língua, seja porque eles não podem falar (como os bebés em uma creche, mesmo bastante interativos), que o método positivista é o único aplicável.

O secundo problema é diferente: trata-se da ação na durée, que acabamos de ver que é bastante mais frequente, importante, significante e estruturante do que dizem. Ora, a ação na durée -um curso de ação- é difícil e bastante custoso de observar continuamente: basta retomar um a um os exemplos de cursos de ação citados mais acima para se convencer. É plausível pedir ao indivíduo sujeito da ação para apontar por escrito as principais características de sua ação, mas com isso perde-se enormemente em informação: não somente quase tudo que diz respeito aos significados, mas também bastante de informações factuais sobre, por exemplo, as características precisas dos contextos e obstáculos encontrados. Pode-se então imaginar estudar por meio de um questionário padrão um tipo específico de curso de ação realizado em paralelo por vários indivíduos? É possível, mas o resultado seria tão pobre em conteúdo... Sem dúvida, é o motivo pelo qual há tão poucos surveys sobre a passagem de assalariado ao trabalho autônomo (self-employment).

Um curso de ação, isso se narra. E aquele que pode contá-lo melhor é, evidentemente, aquele ou aquela que a conduziu do início ao fim. Mesmo se ele modificar a história um pouco, por razões diferentes, o resultado será bastante mais rico em informação factual e em percepção sobre os significados subjetivos que qualquer questionário ou uma hipotética, mas impossível, observação direta. Sobretudo se a entrevista foi relativamente bem conduzida, deixando ao entrevistado (ao "sujeito") uma grande liberdade, mas trazendo-o na medida do possível ao tema da entrevista. Esse resultado é o que chamamos de uma história de vida. ${ }^{12}$

\section{Da rejeição "objetivista" da história de vida ao narrativismo, sua cópia "subjetivista"}

Eu direi um pouco mais adiante como, ainda jovem engenheiro, descobri graças às obras de Oscar Lewis as formidáveis potencialidades informativas e expressivas da história de vida. Como, tendo obtido um emprego de sociólogo mas para fazer pesquisa quantitativa sobre a mobilidade social, eu concebi e

\footnotetext{
${ }^{12}$ Em meu livro Le récit de vie (Bertaux, 2009) eu queria dar o máximo de exemplos de condução de uma entrevista narrativa para que os futuros entrevistadores tivessem confiança em suas capacidades. Para mim já existe história de vida desde que uma pessoa se coloca a falar sob forma narrativa deste ou daquele momento de seu passado pessoal, ou desta ou daquela dimensão de sua existência - profissional por exemplo-, excluindo outras dimensões. Dito de outra forma, não é necessário que uma história de vida seja "completa" para que se possa chamá-la de história de vida.
} 
conduzi em paralelo, quase clandestinamente, uma pesquisa usando histórias de vida sobre a panificação artesanal na França, um setor que empregava 1\% da população ativa. E como, graças à coleta de cerca de 80 histórias de vida a partir de categorias diferentes, operários, artesãos, padeiros, aprendizes... eu consegui, pelo menos creio, adentrar no âmbito íntimo, escondido, os inner workings do funcionamento desse ramo artesanal; e as razões de sua improvável sobrevivência até o dia de hoje.

Mas antes quero chamar a atenção do leitor para um paradoxo. Durante muito tempo o cientificismo que dominou a sociologia na França e no mundo anglo-saxão considerou com grande desprezo a história de vida, este "método do senso comum", como o qualificou Bourdieu com grande veemência ${ }^{13}$ (e sem se dar ao trabalho de se informar minimamente antes de julgar e condenar). Mas a "virada narrativa", o narrative turn, que conduziu ao sucesso do narrativismo nos Estados Unidos, no fundo não mudou nada, contrariamente às aparências. $\mathrm{O}$ positivismo cientificista $\mathrm{e} o$ narrativismo convergem de fato à ideia (falsa) que a história de vida é demasiadamente subjetiva para trazer à sociologia informações objetivas sobre a realidade exterior ao sujeito.

Esse é seu erro comum. Se é verdade que a história de vida é "inteiramente subjetiva de parte a parte" -como negá-lo?- isso não significa de forma alguma que ele não contenha qualquer informação factualmente exata, objetiva, portanto, no sentido positivista do termo. Toda a questão para o sociólogo que a coleta é poder determinar, para cada descrição que é feita, seu grau de verdade objetiva; que esta descrição lida com realidades sóciohistóricas exteriores ao sujeito (as únicas que interessam aos positivistas), ou sobre aspectos de sua própria interioridade da época (as únicas passíveis de interessar aos narrativistas). "Poder determinar...": para os narrativistas, esta ambição é tipicamente positivista, e sem sentido; para os positivistas, ao contrário, ela é simpática mas completamente irrealista.

${ }_{13}$ É uma boa coisa que Bourdieu, em um momento de cólera, redigiu e publicou em sua revista um texto violentamente polêmico contra "o método de histórias de vida", que ele não conhecia senão por ouvir dizer e que ele não tinha feito o esforço de estudar o mínimo. É uma boa coisa, pois se ele não o tivesse feito ninguém acreditaria na argumentação que é desenvolvida aqui. O texto não acrescenta nada à glória do autor; mas ele exprime explicitamente a posição de um dos grandes líderes de opinião da nossa disciplina. Mesmo se Bourdieu (2003) parece ter mudado completamente de opinião alguns anos mais tarde, especialmente em seu posfácio de $A$ miséria do mundo, intitulado "Compreender" não creio que seja o caso. Nesse posfácio -um texto importante de toda forma- ele reconhece a utilidade das entrevistas biográficas, mas somente para documentar a interioridade, os dilemas e os sofrimentos de pessoas cheias de contradições sociais. No entanto, não significa que ele aceita a história de vida como instrumento de observação de cursos de ação e, portanto, como fonte potencial de informações sobre as realidades materiais ou sociais exteriores às próprias pessoas. 
Ora, basta multiplicar as histórias de vida em um mesmo "mundo social" para que se sobreponham entre eles, cada um encarnando assim diante dos outros a função crucial de "determinação do grau de verdade objetiva".

$\mathrm{O}$ próprio Ricoeur, promovendo o método hermenêutico (que visa descobrir significados escondidos contidos em um texto), afirmou com frequência que o que o interessava de fato, não era o texto, mas a ação. Ele permaneceu, contudo, um filósofo, à vontade no mundo das ideias e palavras. Mas a quase totalidade dos scholars que se engajaram na virada narrativa, apaixonados pelos textos e as formas narrativas, decididamente viraram as costas às realidades out there, sobre as quais falam os textos.

Não se pode evidentemente censurar esta atitude nos psicólogos, nos especialistas em estudos literários, aos filósofos, aos linguistas, que não se interessam pelo "refere-se...". Ao contrário, entre os sociólogos, que se espera estudar e compreender o mundo lá fora, esta atitude é mais surpreendente; e mais decepcionante.

O exemplo típico de um estudo narrativista se apresenta assim: um universitário estadunidense passa algum tempo a ler e reler a transcrição de uma entrevista do tipo história de vida (life story) afim de extrair os significados escondidos. Como ele ou ela não pode ir verificar qualquer dos fatos que são citados pelo narrador, nem qualquer das ações que ele/ela afirma ter feito, como lhe parece, portanto, de fato impossível e, além disso, meaningless (sem sentido) estabelecer a verdade de cada ponto da história, ele conclui que tudo que ele ou ela pode fazer dessa história é estudá-la como texto. Resta a ele encontrar o que o autor desse "texto" procurava dizer, conscientemente ou não. Em termos operacionais, não teremos aprendido nada sobre o mundo exterior. Mas teremos compreendido melhor o interior de uma pessoa particular.

So what? A virada narrativa chega a um impasse. E atrás de seus muros altos, a ilusão cientificista se satisfaz de ter sido capaz de desviar as hordas de narrativistas em direção a outros horizontes. Pena...

Há coisa melhor a fazer. Ao invés de se deter à análise hermenêutica de uma única história de vida, aquela de uma pessoa que viveu em um contexto que ignoramos tudo, deve-se multiplicar as históricas de vida no interior, por exemplo, de um mesmo mundo social: depois tudo muda, e o conhecimento sociológico pode avançar. Estou em condições de afirmá-lo, pois eu o experimentei.

\section{Um estudo sobre a panificação artesanal}

Bem antes de me tornar sociólogo, na época em que ainda era engenheiro, me debrucei sobre a tradução francesa do livro Os filhos de Sanches, de Oscar 
Lewis. Esse livro mudou minha vida: após tê-lo lido, decidi que o que eu gostaria de fazer era isso. Paralelamente ao meu trabalho de engenheiro, eu comecei os estudos de sociologia (eu poderia ter podido escolher antropologia; mas eu estava muito mal informado). E quando consegui entrar no CNRS (Centro Nacional de Pesquisa Social) -enquanto pesquisador da sociologia dedicado a estudar a mobilidade social por métodos quantitativos...- eu rapidamente decidi conduzir, em paralelo ao meu trabalho oficial, um estudo por meio de histórias de vida. Os acontecimentos extraordinários de maio-junho de 1968 haviam acabado de revelar, como quando a névoa é rompida, que a sociedade francesa ainda estava estruturada por implacáveis relações de classe. Mas a névoa rapidamente se refez. Eu então pensei que um estudo empírico sobre a produção de um objeto bastante cotidiano revelaria a centralidade escondida das relações de produção e de classe. Eu então decidi estudar a produção de pão.

Inicialmente, eu não conhecia nada. Sabia apenas que, segundo as estatísticas nacionais, 95\% do pão vendido na França vinha de 35.000 padarias artesanais (e apenas $5 \%$ de panificadoras industriais). O setor de panificação empregava em torno de 110.000 operários e aprendizes, e 20.000 vendedores. No total eram 200.000 pessoas, se juntar os padeiros e suas esposas, ou seja, $1 \%$ da população ativa.

Após ter falhado em entrevistar padeiros (devo dizer que ingenuamente eu me apresentava a eles como um sociólogo -o termo não lhes dizia nadarealizando um "estudo": esta palavra os deixou de orelha em pé, eles me perguntavam imediatamente quem me pagava, e quando eu respondia orgulhosamente que era o CNRS, uma instituição do estado, eles faziam uma careta, pois eu percebi muito tempo depois o significado (estado=fiscalização) e subitamente descobriam que estavam ocupados demais para me ceder um momento...), comecei então um estudo com velhos padeiros encontrados na sede do sindicato, que, por sua vez, me acolheram calorosamente e, de bom grado, me contaram suas vidas. Após apenas umas quinze histórias de vida eu já tinha compreendido muitas coisas sobre o funcionamento deste setor artesanal.

Faltava entrevistar padeiros e padeiras artesanais; pedi à minha esposa Isabelle Bertaux-Wiame, que tinha uma formação de historiadora e cujo pai era artesão, para me ajudar.

Os velhos sindicalistas tinham deixado claro que todos os padeiros (comerciantes artesãos autônomos) eram, eles próprios, filhos ou genros de padeiros. Era de fato o caso até 1914, como o indicava os raros arquivos que tratavam desse setor artesanal de produção-venda e que Isabelle havia lido. 
Foram as histórias de vida que nos fizeram compreender pouco a pouco que não era mais assim. Pouco a pouco descobrimos que com a modernização, os filhos de padeiros tendiam cada vez mais (a partir dos conselhos sussurrados por suas mães) a estudar e procurar uma profissão menos dura. É por isso que os casais de padeiros que desejavam se aposentar, não encontravam um único filho de padeiro-artesão para continuar seu negócio. Apenas operáriospadeiros se apresentavam a eles; mas estes não tinham o dinheiro da entrada para comprar... ${ }^{14}$

Após esta longa pesquisa eu estava em condições de dizer alguma coisa sensata sobre a passagem do assalariado ao trabalho autônomo na panificação artesanal. Mas somente nesse setor artesanal. O que eu poderia dizer era especifico a esse setor. Eu não acreditei um instante que os mecanismos e processos que nós descobrimos e que foram abundantemente "verificados", isto é, confirmados pela recorrência, fossem os mesmos do açougue, um comércioartesanal de casal em que os artesãos subsistem ainda; nos cafés que os turistas consideram como característico de Paris e das grandes cidades francesas, mas que são todos mantidos por homens e mulheres originários de pequenas cidades para as quais eles pensam dia e noite voltar na sua aposentadoria; nos restaurantes, uma "indústria" que sem dúvida alguma possui suas próprias regras de funcionamento; nos salões de beleza, frequentemente mantidos por mulheres; no conserto de automóveis (oficinas); apenas para mencionar alguns dos setores de comércio artesanal urbano.

\footnotetext{
${ }^{14}$ As histórias de vida de velhos operários que conseguiram se tornar autônomos como artesãos (padeiro) nos ensinaram enormemente. Eram histórias épicas; pois todos eram de origem rural pobre - como a grande maioria dos padeiros-operários, antigos aprendizes recrutados pelo padeiro da vila, explorados depois devolvidos aos vilarejos quando eles ousavam, ao final de três anos de trabalho penoso, pedir para serem pagos. Quase todos esses jovens operários tinham o projeto de um dia se tornarem autônomos. Mas para isso deveriam encontrar não apenas os recursos necessários para comprar um fundo de padaria, coisa aparentemente impossível (não se empresta aos pobres); além disso, encontrar uma mulher que queira ousar com eles a aventura improvável da metamorfose do proletário em comerciante. O casal teria que resistir durante oito longos anos, o tempo de reembolsar o empréstimo que eles haviam feito. Mas quem os havia emprestado dinheiro? De fato, como descobrimos ao final, foi o velho casal de padeiros que, procurando vender os fundos, "antecipou". O processo que descrevo aqui não é retirado de um único caso, nem de dez, mas de mais de sessenta histórias de vida, e sobretudo de uma compreensão profunda das lógicas de situação e de lógicas de ação de diversos protagonistas (velhos padeiros, jovens operários ambiciosos, mulheres do campo...). Isabelle e eu recolhemos mais de trinta histórias de vida de padeiros, e -ajudados por Renée Colin- quase o mesmo tanto de histórias de vida de padeiros na região parisiense e na região rural do sudeste da França. Nós não procuramos construir uma tipologia, mas identificar as lógicas (de situação e de ação). Nós procuramos compreender o funcionamento interno, os inner workings desse setor. Pensamos ter conseguido. O relatório de pesquisa está disponível no site <www.daniel-bertaux.com>. Ver Daniel Bertaux e Isabelle Bertaux-Wiame Artisanal bakery in France (1981) e Mistérios da baguete (1987).
} 
O que isso significa é que não há caminho milagroso em direção ao conhecimento: primeiro sociográfico, depois somente sociológico (isto é, sócio-histórico) de uma dada sociedade. Nada de atalho: nem pela empiria (o estudo estatístico), nem pela teoria (a teorização de gabinete). Se queremos conhecer, realmente conhecer como se faz a passagem de assalariado ao self-employment em uma dada sociedade -ou seja: no Brasil, nos Estados Unidos...- não há outra solução senão multiplicar os estudos, setor por setor. E em cada setor, multiplicar as entrevistas narrativas com pessoas que efetivamente vivenciaram e agiram nessa passagem, por meio de cursos de ação específicos, mas que apresentam certamente pontos em comum, que é exatamente o que procura o ou a sociólogo(a)..$^{15}$

\section{Generalizar: na sociologia, quais são as condições de possibilidade?}

Sustento, portanto, que não é porque pensamos ter compreendido as lógicas internas (inner workings) do funcionamento de um dos setores artesanais (ou industriais, ou comerciais, ou de serviços...) de uma sociedade desenvolvida que estamos em condições de generalizar para outros setores a presença ativa dessas lógicas. Crer que se estaria em posição de generalizar faria colocar um postulado, que proponho denominá-lo aqui postulado da homogeneidade. Estamos de tal maneira habituados, nós, sociólogos, a fazer esse postulado, que se tornou para nós uma segunda natureza, um reflexo espontâneo que fazemos sem pensar. De uma certa maneira nós precisamos desse postulado; se não o fizermos nós nos sentiremos incapazes de generalizar. Ora, nós nos pensamos como sociólogos, não como sociógrafos; acreditamos que nossa tarefa é de explicar, ou ao menos de propor generalizações plausíveis, e não apenas descrições monográficas. ${ }^{16} \mathrm{E}$ para poder generalizar estamos de alguma maneira obrigados a acreditar na homogeneidade de nossa sociedade.

${ }^{15}$ É aqui que se encontra a resposta aos espíritos fortes que afirmam -sem, no entanto, nunca ter feito a experiência- que toda história de vida é fatalmente deformada pelas insuficiências da memória, as reconstruções, o desejo de se valorizar, os silêncios sobre as situações e as ações vergonhosas... Essas críticas são válidas (elas são igualmente aplicáveis às respostas a um questionário padronizado...), mas na prática parece que a multiplicação de histórias de vida no âmbito de um mesmo setor de produção, ou mais genericamente de um mesmo mundo social (Becker) ou de uma mesma "categoria de situação", ao invés de multiplicar os erros, tende a anulá-los; pois as histórias, mesmo divergindo quanto ao grau de experiências, de imaginários e de narcisismos, convergem necessariamente para os pontos estruturais, uma espécie de pontos de passagem obrigatória.

${ }^{16}$ Nós ainda não compreendemos que uma boa descrição em profundidade, uma thick description (descrição densa), como define muito bem Clifford Geertz, faz avançar mais o conhecimento que um conjunto de generalizações imaginárias, mas arbitrárias. 
Sustento aqui que é uma deformação profissional específica de determinadas ciências sociais, a sociologia mas também, parece-me, a economia.

Nós, sociólogos, estudamos como profissionais uma sociedade que na maior parte do tempo é a mesma que aquela na qual nós crescemos, e que, portanto, também conhecemos (e sobretudo?) por experiência direta. $\mathrm{Na}$ realidade, nós crescemos apenas em um de seus microambientes socioespaciais particulares, e em uma época particular. No entanto, temos a tendência de esquecer disso; e a pensar que em outros microambientes, em outras subculturas de classe, em outras épocas e sobretudo na época atual, até que se prove explicitamente o contrário, as coisas se passam como vimos por experiência pessoal que ocorreram. Não é completamente falso; mas isso tampouco é inteiramente verdadeiro, longe disso!

Admitamos que nós tenhamos algumas desculpas. Nossa corporação defende a ideia que nós exercemos um trabalho científico. Quando uma instituição pública ou privada propõe a um de nós financiar uma pesquisa, é em função da ideia de que ele é um cientista que possui a capacidade (específica de nossa profissão) de produzir, com base em um estudo empírico, generalizações cientificamente verdadeiras em toda a extensão de nossa sociedade; para dizer a verdade, em cada um de seus pontos.

E, claro, se nosso colega começa lembrando-os que a verdadeira atitude científica é de que não se tem certeza de nada; que o verdadeiro espírito científico é a dúvida, então as autoridades se dirigem imediatamente a qualquer um outro: elas não querem lidar com alguém que tem dúvida, mas com alguém que sabe.

Ou ao menos que dá a impressão tranquilizadora de saber.

Nós mesmos, se queremos construir uma casa ou uma ponte preferimos nos dirigir a um arquiteto ou um engenheiro que dá a impressão de conhecer perfeitamente seu trabalho. Mas seus conhecimentos técnicos e práticos se sustentam sobre as bases sólidas de conhecimentos universais -válidos em todos os lugares e todos os tempos-demonstrados pelo cálculo e repetidamente verificados; conhecimentos científicos que eles aplicam cotidianamente em seu trabalho. Podemos dizer o mesmo da sociologia aplicada?

Não importa a disciplina científica, toda generalização repousa sobre o postulado da homogeneidade: sobre a ideia que as leis físicas -as reações químicas- são universais, são apresentadas e ativadas em todos os lugares e em todo tempo (pelo menos em nossa escala). E que elas são apresentadas e ativadas permanentemente não como "leis" ou mesmo como regularidades estatísticas, mas sempre com a mesma precisão absoluta. É por isso que realmente seria total falta de cultura científica, e ignorar tudo do verdadeiro 
espírito científico, ousar afirmar que a sociologia é ou se tornará "uma ciência como as outras ciências". Citou-se Durkheim abundantemente a esse respeito: "Deve-se tratar os fatos sociais como coisas", mas ele não diz que os fatos sociais são coisas; ele quer dizer que se queremos descobrir suas lógicas de produção e de funcionamento deve-se habituar a encará-los como se eles fossem regidos por forças impessoais, supraindividuais, "coletivas". Ele também escreveu que a vida social gera permanentemente situações quaseexperimentais, porque ele é perfeitamente consciente da maneira como a pesquisa científica avança: pelo método experimental. Mas evidente, uma situação quase-experimental produzida pela vida sócio-histórica é ainda muito distante $-\mathrm{e}$ qualitativamente diferente- de uma situação verdadeiramente experimental, produzida (designed) artificialmente em função de uma hipótese a ser verificada pelo método experimental. Durkheim certamente abriu o canal ao cientificismo; mas ele foi inteligente e cultivado demais para sucumbir.

Esse não foi o caso de sociólogos das gerações seguintes, aqueles de que somos mais ou menos obrigados a assumir a herança.

Por exemplo, a ideia de utilizar a história de vida como instrumento de conhecimento empírico de cursos de ação individuais foi combatida muito violentamente; principalmente, mas não apenas, por Bourdieu. Afinal, por que essa violência? Porque sob uma aparência inocente, etnográfica, humanista, esta simples ideia ameaçava estourar a enorme bolha cientificista que mantinha viva toda profissão, e particularmente seus líderes.

Ao multiplicar as histórias de vida, não de forma aleatória de encontros, mas no âmbito de ambientes socioprofissionais - de "mundos sociais"- ou de categorias de situações dadas (ver Bertaux, 2009), teríamos de fato chegado a colocar em questão não apenas um único, mas vários postulados sobre os quais baseava a bolha cientificista:

- O postulado naturalista (do qual os postulados funcionalista e estruturalista constituem variantes)

Segue a ideia de que tudo se passa como se as sociedades humanas fossem transformadas por leis imanentes, coletivas, que escapam à consciência dos indivíduos ${ }^{17}$ e de grupos (apenas os melhores sociólogos podem percebê-las...), e que agem sobre as costas dos indivíduos, retirando-lhes assim todo grau de liberdade e tornando suas condutas previsíveis, senão ao nível das condutas individuais, pelo menos ao nível dos grupos. Quanto mais avançamos

17 "Não se pode pedir às pessoas que façam sua própria sociologia"; e "A maldição das ciências humanas é talvez ter que lidar com objetos que falam", duas frases extraídas do livro Le métier de sociologue de Bourdieu et al. (1968). 
no conhecimento, se sedimentam nos cursos de ação individuais estratégias colocadas em prática com paciência e fúria, e da presença ativa, em paralelo às forças poderosas de interesses pessoais, aquelas menos poderosas (mas cheias de convicções morais e de espírito de solidariedade), mais duvidamos do postulado naturalista, mais iríamos nos aproximar da concepção esboçada por Max Weber, afirmada por Sartre (embora eu duvide que ele tenha se interessado por Weber, mas que conhecia bem a filosofia alemã, de Kant e Hegel a Husserl via Heidegger), e fortemente representado na sociologia francesa por Raymond Boudon e seu "individualismo metodológico. ${ }^{18}$

\section{- O postulado da homogeneidade}

Trata-se aqui de uma ideia mais original que a anterior. Não tenho o espaço para desenvolvê-la aqui. Penso que se se afirma que o postulado da homogeneidade não se verifica, se, antes, é a heterogeneidade que predomina na maioria das "sociedades" das quais falam os sociólogos -de fato, nos Estados Unidos modernos- isso muda bastante as coisas para nós sociólogos. O Brasil constitui evidentemente um caso extremo de heterogeneidade. Mas a maioria dos países são heterogêneos em um certo grau, mesmo os países pequenos (a Suíça ou a Bélgica, por exemplo; e, evidentemente, as ex-colônias tornadas países independentes, cujas fronteiras foram traçadas arbitrariamente...). ${ }^{19}$ Isso todo mundo sabe; entretanto, quase todo mundo, e em particular os sociólogos, continuam a considerar as médias estatísticas nacionais como resultados científicos, enquanto essas médias não apenas excluem as diferenças, mas descrevem uma situação que não existe em nenhum lugar (pensemos, por exemplo, na Itália dividida entre um norte e

${ }^{18}$ Criada no fim dos anos 1970 por Boudon e seu colega Bourricaud, esta expressão significava inicialmente a vontade de se opor ao estruturalismo triunfante à época, colocando o postulado que uma sociedade humana se compõe unicamente de indivíduos e de suas relações: os macrotemas tais como as classes sociais, o estado, as instituições... não existem sem os indivíduos que os compõem e suas interações. Na época, esta concepção foi percebida como produzindo uma ruptura franca e violenta com o conjunto da tradição sociológica de seus fundadores (founding fathers). O sociólogo Jon Elster, próximo das concepções de Boudon, mostrou no entanto que se pode ler Marx ("Os homens fazem a história...") como precursor desta concepção... Boudon afirmou em seguida que sua concepção não era outra coisa senão uma sociologia da ação, sublinhando assim que o que separava mais claramente sua sociologia daquela de Bourdieu era considerar a ação como relativamente autônoma; o que confirma plenamente a tese sustentada no presente artigo. Os dois homens pertenciam à mesma geração; ambos tinham formação filosófica; no entanto, tudo os separava e eles se combateram violentamente durante toda sua vida.

${ }^{19}$ Para uma ilustração forte da ideia de heterogeneidade eu sugiro ao leitor o artigo notável de Giovanni Contini (1997) sobre três vilarejos da Toscana. O autor, historiador e sociólogo, mostra como esses vilarejos e seus habitantes conheceram no espaço de duas gerações destinos completamente diferentes em função de efeitos imprevistos da globalização sobre suas economias locais. 
um centro muito desenvolvidos e ricos, e um sul subdesenvolvido). Evidente que os métodos extensivos, estatísticas sociais e surveys são os únicos que permitem descrever com alguma precisão essas diferenças. Mas eles não estão de maneira alguma em condição de descrever os processos que engendraram essas diferenças. Por isso, deve-se recorrer a outros métodos de observação, a métodos ditos "intensivos", centrando o estudo sobre um território particular; o que põe em seguida a questão da generalização dos resultados do estudo a outros territórios. É evidente que esta generalização só é possível no interior do espaço regional em que estão apresentadas e ativadas as mesmas lógicas da situação e as mesmas lógicas de ação daquelas que foram observadas e incluídas em um pequeno território... É aqui que encontramos seus limites as ideias de recorrência das observações e de saturação que propus como permitindo a generalização a partir de observações "qualitativas" ou, antes, "intensivas"; como, de alguma maneira, o equivalente metodológico da amostra representativa para os métodos extensivos (Bertaux e Bertaux-Wiame, 1981).

Frequentemente, quando evoco diante de colegas a necessidade de multiplicar os estudos sócio-antropológicos, uma consequência lógica do meu postulado da heterogeneidade, eles respondem que demandaria demasiada energia, dinheiro e tempo. Mas não estou convencido: a soma total do que atualmente é alocado por milhares de sociólogos profissionais é bastante considerável, mas não vejo se esboçar perspectivas de acumulação razoável. Parece-me que andamos em círculo há muito tempo, talvez porque ninguém ousa estourar a bolha...

\section{Referências}

BELLAH, Robert et al. Habits of the heart: individualism and commitment in American life. Berkeley: University of California Press, 1985.

BERGER, Peter; LUCKMANN, Thomas. A construção social da realidade: tratado de sociologia do conhecimento. $4^{\mathrm{a}}$ ed. Petrópolis: Vozes, 1978 (orig.: The social construction of reality: a treatise in the sociology of knowledge, Anchor Books, 1966).

BERTAUX, Daniel. Le récit de vie. Paris: Nathan, 2009.

BERTAUX, Daniel. Destins personnels et structure de classe. Paris: P. U. F., 1977 (tradução para o português de José Saramago, Destinos pessoais e estrutura de classe, Edições Morais, 1978).

BERTAUX, Daniel. Reasons of the heart: comparing collective subjectivity and moral choices in the sixties student movement. In: Else Oyen (Org.). Comparative methodology, theory and practice in international social research. London: Sage, 1990. 
BERTAUX, Daniel; BERTAUX-WIAME, Isabelle. Artisanal bakery in France: how it lives and why it survives. In: F. Bechhofer; B. Elliott (Orgs.). The petite bourgeoisie: comparative studies of the uneasy stratum. London: MacMillan, 1981.

BERTAUX, Daniel; BERTAUX-WIAME, Isabelle. Mistérios da baguete: padarias artesanais na França - como vivem e por que sobrevivem. Novos Estudos do Cebrap, v. 19, p. 116-142, 1987.

BOURDIEU, Pierre. A miséria do mundo. Petrópolis: Vozes, 2003.

BOURDIEU, Pierre. Question de sociologie. Paris: Minuit, 1980.

BOURDIEU, Pierre; PASSERON, Jean-Claude. Sociology and philosophy in France since 1945: death and resurrection of a philosophy without subject. Social Research, v. 34, n. 1, p. 162-212, 1967.

BOURDIEU, Pierre; PASSERON, Jean-Claude; CHAMBOREDON, J. C. Le métier de sociologue. Paris: Mouton de Gruyter, 1968.

CONTINI, Giovanni. The local worldview: social change and memory in three Tuscan communes. In: D. Bertaux; P. Thompson (Orgs.). Pathways to social class. Oxford: Clarendon Press, 1997.

DELCROIX, Catherine. Ressources subjetives et construction d'un capital d'experiénce biographique: l'exemple des médiatrices socioculturelles. In: C. Dardy; C. Frétigné (Orgs.). L'experience professsionelle et personelles en question. Paris: L'Harmattan, "Mondes Sociaux", 2004.

ERIKSON, Erik. Childhood and society. New York: Norton, 1950.

FRASER, Ronald et al. 1968: a student generation in revolt. London: Chatto and Windus, 1988.

LEPENIES, Wolf. As três culturas. São Paulo: Edusp, 1996.

PASSERON, Jean-Claude. Le raisonnement sociologique. Paris: Nathan, 1991.

RICOEUR, Paul. Tempo e narrativa. São Paulo: WMF Martins Fontes, 2011. 3 v.

SUCHMAN, Lucy. Plans and situated action. New York: Cambridge University Press, 1987.

Recebido em: 8 set. 2013

Aprovado em: 14 abr. 2014

Autor correspondente:

Daniel Bertaux

Laboratoire Dynamique Européennes

Université de Strasbourg/Misha

5 Avenue du Général Rouvillois

67000 Strasbourg, França 